\title{
Neuroimaging findings in pediatric sports-related concussion
}

\author{
Michael J. Ellis, MD, ,2,2,4,67 Jeff Leiter, PhD, ${ }^{1,6}$ Thomas Hall, BSc, ${ }^{6}$ Patrick J. McDonald, MD, MHSc, $, 1,2,4,6,7$ \\ Scott Sawyer, MD, ${ }^{2,5}$ Norm Silver, MD, ${ }^{2,5}$ Martin Bunge, MD, ${ }^{3}$ and Marco Essig, MD ${ }^{3}$ \\ Departments of ${ }^{1}$ Surgery, ${ }^{2}$ Pediatrics and Child Health, and ${ }^{3}$ Diagnostic Imaging and ${ }^{4}$ Section of Neurosurgery, University of \\ Manitoba, ${ }^{5} \mathrm{Health}$ Sciences Centre Children's Hospital, ${ }^{6} \mathrm{Pan}$ Am Clinic, and ${ }^{7}$ Children's Hospital Research Institute of Manitoba, \\ Canada North Concussion Network, Winnipeg, Manitoba, Canada
}

\begin{abstract}
OBJECT The goal in this review was to summarize the results of clinical neuroimaging studies performed in patients with sports-related concussion (SRC) who were referred to a multidisciplinary pediatric concussion program.

METHODS The authors conducted a retrospective review of medical records and neuroimaging findings for all patients referred to a multidisciplinary pediatric concussion program between September 2013 and July 2014. Inclusion criteria were as follows: 1) age $\leq 19$ years; and 2) physician-diagnosed SRC. All patients underwent evaluation and follow-up by the same neurosurgeon. The 2 outcomes examined in this review were the frequency of neuroimaging studies performed in this population (including CT and MRI) and the findings of those studies. Clinical indications for neuroimaging and the impact of neuroimaging findings on clinical decision making were summarized where available. This investigation was approved by the local institutional ethics review board.
\end{abstract}

RESULTS A total of 151 patients (mean age 14 years, 59\% female) were included this study. Overall, 36 patients (24\%) underwent neuroimaging studies, the results of which were normal in $78 \%$ of cases. Sixteen percent of patients underwent CT imaging; results were normal in $79 \%$ of cases. Abnormal CT findings included the following: arachnoid cyst (1 patient), skull fracture (2 patients), suspected intracranial hemorrhage (1 patient), and suspected hemorrhage into an arachnoid cyst (1 patient). Eleven percent of patients underwent MRI; results were normal in $75 \%$ of cases. Abnormal MRI findings included the following: intraparenchymal hemorrhage and sylvian fissure arachnoid cyst (1 patient); nonhemorrhagic contusion (1 patient); demyelinating disease (1 patient); and posterior fossa arachnoid cyst, cerebellar volume loss, and nonspecific white matter changes (1 patient).

CONCLUSIONS Results of clinical neuroimaging studies are normal in the majority of pediatric patients with SRC. However, in selected cases neuroimaging can provide information that impacts decision making about return to play and retirement from the sport.

http://thejns.org/doi/abs/10.3171/2015.1.PEDS14510

KEY WORDS neuroimaging; sports-related concussion; pediatric patients; computed tomography; magnetic resonance imaging; trauma

$\mathrm{S}$ PORTS-RELATED concussion (SRC) is a form of traumatic brain injury (TBI) representing an emerging public health concern that affects approximately 1.6-3.8 million Americans ${ }^{26}$ annually, with a significant proportion occurring in children and adolescents. The clinical presentation of acute SRC among pediatric patients is highly variable, often manifesting as a combination of physical, psychological, sleep, and affective symptoms. The vast majority of these patients will achieve complete neurological recovery within 1-4 weeks; however, $15 \%-20 \%$ will develop postconcussion syndrome, a condition characterized by persistent symptoms lasting more than 1-3 months. ${ }^{13,17,34,40}$ Some consensus statements suggest that the mainstay of management for children and adolescents with SRC is physical and cognitive rest followed by gradual reintegration into full sport and school activities. $19,22,31-33$

Evidence from experimental animal studies suggests

ABBREVIATIONS GRE = gradient recalled echo; ICH = intracranial hemorrhage; IPH = intraparenchymal hemorrhage; LOC = loss of consciousness; $\mathrm{mTBI}=$ mild traumatic brain injury; SRC = sports-related concussion; SWI = susceptibility-weighted imaging.

SUBMITTED September 26, 2014. ACCEPTED January 12, 2015.

INCLUDE WHEN CITING Published online June 2, 2015; DOI: 10.3171/2015.1.PEDS14510.

DISCLOSURE The authors report no conflict of interest concerning the materials or methods used in this study or the findings specified in this paper. The Pan Am Clinic

Foundation provided financial support for this study. 
that SRC results in temporary alterations in neuronal energy metabolism, excitatory neurotransmitter release, and cerebral blood flow, ${ }^{12,18}$ constituting a functional rather than a structural brain injury. Operating on this evidence, various national and international organizations have published position statements in which they concluded that neuroimaging findings are normal in patients with SRC and that these studies add little to the clinical management of this condition., ${ }^{4,19,31-33}$ At present, experts recommend that neuroimaging be used only in acutely injured patients in whom there is suspicion of serious intracranial pathological conditions such as subdural hematoma, epidural hematoma, or intraparenchymal hemorrhage (IPH), or in patients with prolonged disturbance in level of consciousness, focal neurological deficits, or worsening symptoms., ${ }^{419,21,22,31-33}$ Despite significant consistency across published position statements, $4,19,21,22,31-33$ these recommendations are derived from expert opinion only (Level 5 evidence).

In recent years, several advances in structural neuroimaging techniques have led to improved detection of parenchymal abnormalities associated with TBI. Susceptibility-weighted imaging (SWI) and gradient recalled echo (GRE) sequences that are exquisitely sensitive to the magnetic properties of blood have permitted the visualization of traumatic axonal injury and cerebral microhemorrhages in pediatric patients with TBI., ${ }^{2,5-7,41,42}$ Although preliminary research studies have failed to detect similar abnormalities in pediatric patients with $\mathrm{SRC}^{29}$ and mild TBI (mTBI), ${ }^{30,43}$ research studies often include subjects with no clinically defined indication for neuroimaging. Although previous neuroimaging studies of mTBI in children and adolescents have included patients participating in sports, ${ }^{23,30,36,41}$ we are not aware of any published studies that have examined clinical neuroimaging findings among an exclusive cohort of pediatric patients with SRC. Furthermore, there are currently no evidence-based returnto-play or retirement practice guidelines for children and adolescents with SRC who demonstrate traumatic lesions on clinical neuroimaging studies.

Accordingly, the purpose of this retrospective review was to summarize the results of clinical neuroimaging studies performed in patients with SRC who were referred to and treated at a multidisciplinary pediatric concussion program. The impact of neuroimaging findings on clinical decision making is discussed.

\section{Methods}

\section{Research Design}

We conducted a single-center, retrospective review of medical records and neuroimaging findings for all patients referred to the Pan Am Concussion Program at the Pan Am Clinic in Winnipeg, Manitoba, between September 1, 2013, and July 31, 2014. Patient referrals were obtained from pediatric and adult emergency departments, pediatricians, family practitioners, athletic therapists, and coaches. Inclusion criteria were as follows: 1) age $\leq 19$ years; and 2) neurosurgeon-diagnosed SRC. Exclusion criteria included 1) diagnosed concussion occurring outside of a sporting activity; 2) incomplete medical records; and 3 ) neuroimaging studies that were undertaken as a part of research studies. Concussions sustained during nonspecific gym class and schoolyard activities were excluded. This study was approved by the institutional ethics review board at the University of Manitoba.

\section{Definitions of Terms}

The diagnosis of SRC was determined during initial consultation for all eligible patients by a single neurosurgeon with fellowship training in concussion spectrum disorders, according to the definition set forth by the International Consensus on Concussion in Sport. ${ }^{33}$ Because patients in the study were referred by numerous outside emergency department, pediatric, and family medicine physicians, it was not possible to confirm the diagnostic criteria used initially to refer patients to the Pan Am Concussion Program. Clinical indications for neuroimaging performed prior to referral were also absent for the vast majority of patients. In the case of those patients who underwent neuroimaging while under the care of the Pan Am Concussion Program, all studies were ordered by the same neurosurgeon, based on the patient's clinical history and physical examination findings, and were summarized accordingly. In general, MRI was considered in patients who demonstrated focal neurological deficits or persistent symptoms lasting more than 1-2 months that were not improving, or patients who were referred with abnormal findings on CT imaging studies.

\section{Assessments of SRC}

Neuroimaging studies were performed at multiple hospitals by using multiple CT and MRI scanners. All CT scans performed in this study were obtained without contrast. Magnetic resonance imaging protocols also differed across imaging sites but were summarized accordingly. All neuroimaging studies in this cohort were performed without sedation or general anesthetic.

\section{Statistical Analysis}

Outcomes examined in this review were the frequency of neuroimaging studies performed and their findings. All data related to patient demographic information, neuroimaging studies performed, and neuroimaging outcomes were summarized using descriptive statistics. All statistical analyses were performed using SPSS 22.0 (IBM Corp.).

\section{Results}

During the study period, 212 pediatric patients were referred to the multidisciplinary concussion program. Of those patients, 151 (71\%; 65 male and 86 female) received a diagnosis of SRC on initial consultation by the neurosurgeon and were included in the study. A summary of sports played by pediatric patients with SRC is presented in Table 1. Sixty-one patients were excluded due to concussions sustained outside of a sport setting. The mean age of patients in this cohort was $14.26 \pm 2.21$ years (range 5-19 years). Twenty-four of 151 patients (16\%) underwent CT imaging, all of which occurred in the emergency department, with 23 patients undergoing imaging prior to referral to the concussion program and 1 undergoing urgent 
TABLE 1. Summary of sports played by 151 pediatric patients with SRC

\begin{tabular}{lc}
\hline \multicolumn{1}{c}{ Sport } & \% of Patients* \\
\hline Hockey & 41.72 \\
\hline Soccer & 20.53 \\
\hline Basketball & 7.95 \\
\hline Football & 7.28 \\
\hline Baseball & 4.64 \\
\hline Skiing/snowboarding & 3.97 \\
\hline Ringette & 2.65 \\
\hline Volleyball & 2.65 \\
\hline Rugby & 1.99 \\
\hline Other & 6.62 \\
\hline
\end{tabular}

* Less than $2 \%$ of patients participated in other sporting activities such as figure skating/ice skating, wrestling, dance/gymnastics, swimming, cycling, trampoline, and track and field.

CT after a syncopal episode at home that occurred after consultation with the concussion program. The results of cranial CT imaging were normal in 19 of 24 (79\%) cases, including a patient with a normal anatomical variant of the septum pellucidum. Abnormal CT imaging results included calvarial skull fracture (1 patient), orbital floor fracture (1 patient), posterior fossa arachnoid cyst (1 patient), focal hyperdensity in the basal ganglia suspicious for hemorrhage (1 patient), and isodense lesion in the left sylvian fissure suspicious for hemorrhage into a small sylvian fissure arachnoid cyst (1 patient). There were no cases of definitive intracranial hemorrhage ( $\mathrm{ICH}$ ) observed on CT imaging in this study.

Sixteen of 151 patients (11\%) underwent MRI, including 4 patients who also underwent CT imaging. All MRI studies were performed in the outpatient setting, except 1 performed in a hospitalized patient. All MRI studies were obtained following referral to the concussion program, except 1 obtained prior to referral. Clinical indications for MRI in this study include the following: persistent symptoms (12 patients), focal neurological deficit (1 patient), abnormal CT imaging findings (2 patients), and constitutional symptoms (1 patient). The results of cranial MRI were normal in 12 of $16(75 \%)$ patients. One patient was found to have a cavum septum pellucidum that was classified as a normal finding. Another was found to have bilateral basal ganglia calcifications that were also classified as a normal finding. Abnormal MRI results included the following: IPH and a sylvian fissure arachnoid cyst (1 patient); nonhemorrhagic contusion (1 patient); multifocal demyelinating disease (1 patient); and posterior fossa arachnoid cyst, cerebellar volume loss, and nonspecific white matter changes (1 patient). A summary of patients who underwent MRI is shown in Table 2.

\section{Illustrative Cases Case 1}

An 11-year-old boy sustained a brief loss of consciousness (LOC) after a fall onto the ice during a competitive hockey game. He was previously healthy with no history of concussions or TBI. His family history was significant for a second-generation relative who played professional American football and in whom chronic traumatic encephalopathy was diagnosed on autopsy. The patient was evaluated at a pediatric emergency department, where he complained of headache, nausea, photophobia, and irritability. A CT scan of the brain obtained without contrast demonstrated an extraaxial isodense lesion within the left sylvian fissure that was suspicious for hemorrhage into a small arachnoid cyst. The patient was referred to the multidisciplinary concussion program, where he reported persistent concussion symptoms, including headache, dizziness, and postural imbalance. An MRI study of the brain obtained without contrast was performed 41 days after the injury and confirmed a small left sylvian fissure arachnoid cyst with no evidence of hemorrhage. The GRE imaging revealed a $2.3 \times 1-\mathrm{cm}$ curvilinear hypointense lesion within the right occipital lobe white matter consistent with an IPH that was not observed on any other MR sequences (Fig. 1). The patient remained symptomatic at 144 days postinjury. Based on the traumatic abnormalities identified on clinical neuroimaging findings and the child's prolonged symptoms, the neurosurgeon advised the parents that in his opinion the child should not return to contact sports.

\section{Case 2}

During a ringette game, a 14-year-old girl sustained a fall onto the ice that was not associated with any LOC or amnesia. She was previously healthy, with 1 prior questionable concussion and no history of moderate or severe TBI. She initially became asymptomatic at rest within a few days postinjury but experienced severe headaches on repeated attempts to return to ringette. Two months later, she underwent an MRI study obtained without contrast that demonstrated a left parietooccipital abnormality that was best visualized on T2-weighted and FLAIR sequences (Fig. 2). No evidence of hemorrhage was observed on GRE imaging. Follow-up contrast-enhanced MRI studies performed 7 and 11 months later demonstrated no interval growth of the lesion, making other differential diagnoses such as low-grade glioma less likely. Single-voxel MR spectroscopy performed over the region of interest demonstrated a slightly decreased creatine level relative to choline and $N$-acetylaspartate levels, which correlated with gliosis. Taken together, the neuroimaging features were most consistent with the presence of a nonhemorrhagic parenchymal contusion or gliosis. Formal neuropsychological testing undertaken at 14 months postinjury demonstrated impairments in visual memory, sensory perception, and visuospatial processing. The patient, who was asymptomatic at rest and during physical activity, was referred to the multidisciplinary concussion program for an opinion regarding return to play. Based on the traumatic abnormalities identified on clinical neuroimaging and concordant neuropsychological findings, the neurosurgeon advised the parents that in his opinion the child should not return to contact sports.

\section{Discussion}

This review provides preliminary empirical evidence 
TABLE 2. Summary of pediatric patients with SRC who underwent MRI

\begin{tabular}{|c|c|c|c|c|c|c|}
\hline $\begin{array}{l}\text { Age (yrs), } \\
\text { Sex }\end{array}$ & Sport & Symptoms & Clinical Indication & $\begin{array}{l}\text { Time Since } \\
\text { Injury }\end{array}$ & MRI Details & MRI Results \\
\hline $11, M^{*}$ & Hockey & $\mathrm{HA}$ & Abnormal CT results & 41 days & GRE+, C-, SWI- & $\begin{array}{l}\text { Lt sylvian fissure arachnoid cyst, rt } \\
\text { occipital IPH }\end{array}$ \\
\hline $17, \mathrm{~F}$ & Soccer & HA, polydipsia, cold intolerance & $\begin{array}{l}\text { Constitutional symp- } \\
\text { toms }\end{array}$ & 40 days & $\begin{array}{l}\mathrm{C}+, \text { GRE-, SWI+, } \\
\text { dynamic pitui- } \\
\text { tary study }\end{array}$ & Normal \\
\hline $17, \mathrm{~F}$ & Hockey & $\mathrm{HA}$, blurred vision, dizziness & Persistent symptoms & 238 days & GRE+, C-, SWI- & Normal \\
\hline $14, \mathrm{~F}$ & Soccer & HA, photophobia, dizziness & Persistent symptoms & 183 days & GRE+, C-, SWI- & Normal, cavum septum pellucidum \\
\hline $14, \mathrm{M}$ & Hockey & Blurred vision, $\mathrm{HA}$, vomiting & Focal neuro deficit & 9 days & GRE+, C+, SWI- & $\begin{array}{l}\text { Multifocal demyelinating disease, } \\
\text { optic neuritis }\end{array}$ \\
\hline $14, F^{*}$ & Ringette & $\mathrm{HA}$ & Persistent symptoms & 60 days & GRE+, C+, SWI- & $\begin{array}{l}\text { Lt parietal nonhemorrhagic contu- } \\
\text { sion }\end{array}$ \\
\hline $14, \mathrm{~F}$ & Hockey & HA, fatigue, sleep dist & Persistent symptoms & 176 days & GRE-, C-, SWI- & Normal \\
\hline $18, \mathrm{~F}$ & Hockey & HA, dizziness, visual dist & Persistent symptoms & 170 days & GRE+, TOF MRA & Normal \\
\hline $13, \mathrm{~F}$ & Gymnastics & HA, fatigue, sleep dist & Abnormal CT results & 14 days & $\mathrm{GRE}+, \mathrm{C}+, \mathrm{MRA}$ & $\begin{array}{l}\text { Normal, bilat basal ganglia calcifi- } \\
\text { cations }\end{array}$ \\
\hline $11, \mathrm{M}$ & Hockey & HA, dizziness, photophobia & Persistent symptoms & 154 days & GRE-, SWI+ & Normal \\
\hline $14, \mathrm{M}$ & Volleyball & $\begin{array}{l}\text { HA, decreased concentration, } \\
\text { language processing impair- } \\
\text { ment }\end{array}$ & Persistent symptoms & 180 days & GRE+, C-, SWI- & Normal \\
\hline $15, \mathrm{~F}$ & Basketball & HA, blurred vision, anxiety & Persistent symptoms & 213 days & GRE+, C-, SWI- & Normal \\
\hline $14, \mathrm{M}$ & Hockey & Migraine HA & Persistent symptoms & 131 days & GRE+, C-, SWI+ & Normal \\
\hline $16, \mathrm{~F}$ & Soccer & HA, blurred vision, dizziness & Persistent symptoms & 143 days & GRE+, C-, SWI- & Normal \\
\hline $15, F$ & Baseball & $\mathrm{HA}$ & Persistent symptoms & 199 days & GRE-, C-, SWI- & $\begin{array}{l}\text { PF arachnoid cyst, vol loss in It } \\
\text { cerebellum, nonspecific WM ab- } \\
\text { normalities }\end{array}$ \\
\hline $14, \mathrm{~F}$ & $\begin{array}{l}\text { Figure skat- } \\
\text { ing }\end{array}$ & HA, dizziness, anxiety & Persistent symptoms & 210 days & GRE+, C-, SWI- & Normal \\
\hline
\end{tabular}

C+, C- = study obtained with (+) or without (-) contrast; dist = disturbance; GRE+, GRE- = GRE imaging included (+) or not included (-); HA = headache; MRA = MR angiography; neuro = neurological; PF = posterior fossa; SWI+, SWI- = susceptibility-weighted imaging included (+) or not included (-); TOF = time of flight; WM = white matter.

* Illustrative cases in text.

to suggest that the results of clinical neuroimaging studies performed in children and adolescents with SRC are normal in the vast majority of cases. Overall, the results in 78\% of neuroimaging studies were normal in this retrospective review of patients referred to a multidisciplinary concussion program. The results of CT imaging studies performed exclusively in the emergency department were normal in $79 \%$ of cases. Clinically indicated MRI studies performed almost exclusively in the outpatient setting yielded normal findings in $75 \%$ of cases. Among the patients who underwent neuroimaging studies, traumatic abnormalities were detected in $11 \%$ of cases.

Over the past decade, numerous published position statements from national and international organizations have concluded that neuroimaging studies yield normal findings in the vast majority of patients with SRC, and thus neuroimaging contributes little to the clinical management of these patients., ${ }^{41,31-33}$ Experts suggest that neuroimaging be used only to rule out structural intracranial pathology in patients with impaired level of consciousness, focal neurological deficits, or persistent symptoms., ${ }^{4,19,21,22,31-33}$ Although such recommendations seem reasonable, there are no clinical studies that have examined neuroimaging findings in an exclusive population of children and adolescents with SRC. Consequently, these expert findings and recommendations are based on expert opinion only (Level 5 evidence).

The use of CT imaging in pediatric MTBI has been the focus of several multiinstitutional clinical studies. Despite recent widespread increases in the use of $\mathrm{CT}$ in the evaluation of pediatric mTBI in Canadian and American emergency departments, ${ }^{23}$ only $4 \%-7 \%$ of patients are found to demonstrate an abnormality on CT, with only $0.5 \%$ requiring neurosurgical intervention. ${ }^{15,23}$ Head injury occurring during a sporting activity has consistently failed to be identified as a risk factor for an abnormal CT finding across pediatric studies, which includes other risk factors such as low Glasgow Coma Scale score; suspected open, depressed, or basal skull fractures; persistent headache or irritability; large or boggy scalp hematoma; and dangerous mechanism of injury (i.e., motor vehicle accident, fall from bicycle with no helmet). . $^{3,1624,27,35-37}$ These studies have informed the development of several clinical decision rules that help guide the judicious use of CT imaging 

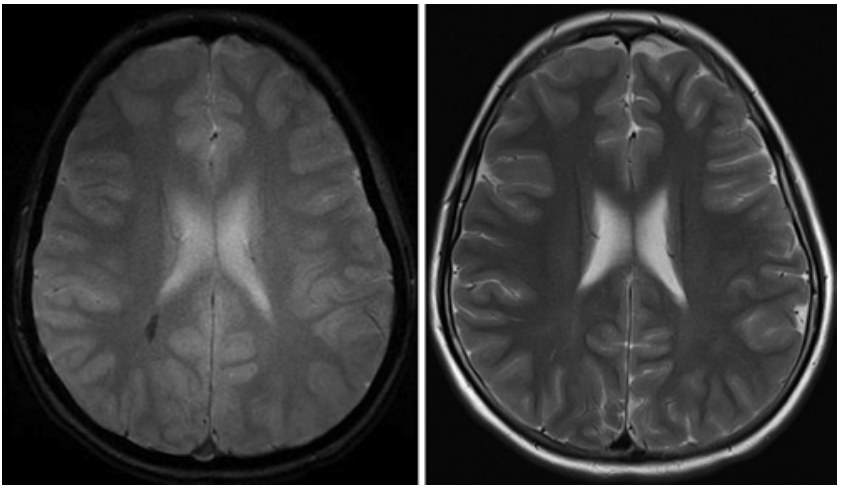

FIG. 1. Illustrative Case 1. Axial GRE image (left) demonstrates curvilinear hypointensity consistent with right occipital IPH that was not visualized on axial T2-weighted MRI (right).

in pediatric patients with mTBI who are evaluated in the emergency department. ${ }^{3,16,24,27,35-37}$

In the present study, $21 \%$ of $\mathrm{CT}$ imaging studies performed by emergency department physicians in patients with suspected SRC demonstrated abnormal findings, including calvarial skull fracture (1 patient), orbital floor fracture (1 patient), suspected ICH (2 patients), and posterior fossa arachnoid cyst (1 patient). One patient was found to have a normal anatomical variant of the septum pellucidum, including a cavum septum pellucidum and a cavum vergae, which was classified as a normal finding and is present in up to $20 \%$ of the general pediatric population on neuroimaging. ${ }^{8}$ Overall, the results of this study and review of the literature suggest that $\mathrm{CT}$ imaging findings are normal in the vast majority of pediatric patients with SRC and mTBI, and that this modality should be reserved for use only in the emergency department to rule out ICH or skull fractures in acutely injured patients with appropriate clinical signs and symptoms. Because of concerns related to the oncological and neurocognitive risks associated with exposure to low doses of ionizing radiation in children, ${ }^{9,20}$ the use of CT outside of the emergency department setting is discouraged.

The use of MRI in pediatric SRC has received significant attention among researchers in recent years. Research series suggest that findings on conventional structural MRI studies are also normal in the vast majority of pediatric patients with mild TBI and SRC; ${ }^{29,30,43}$ however, research cohorts frequently include subjects who are recruited out of convenience and may not have a clinical indication for MRI. In such cases, information is lacking regarding clinically driven MRI findings in pediatric patients with SRC. Abnormal findings were detected in $25 \%$ of MRI studies performed in this series, with $2 \mathrm{MR}$ images demonstrating traumatic abnormalities and 3 contributing directly to clinical decision making. In 1 case, MRI undertaken for blurred vision and vomiting allowed the timely diagnosis of a potentially life-threatening demyelinating disease and permitted urgent treatment resulting in complete neurological recovery and return to sporting activities. In 2 cases, MRI demonstrated hemorrhagic and nonhemorrhagic traumatic lesions that impacted decision making about return to play.
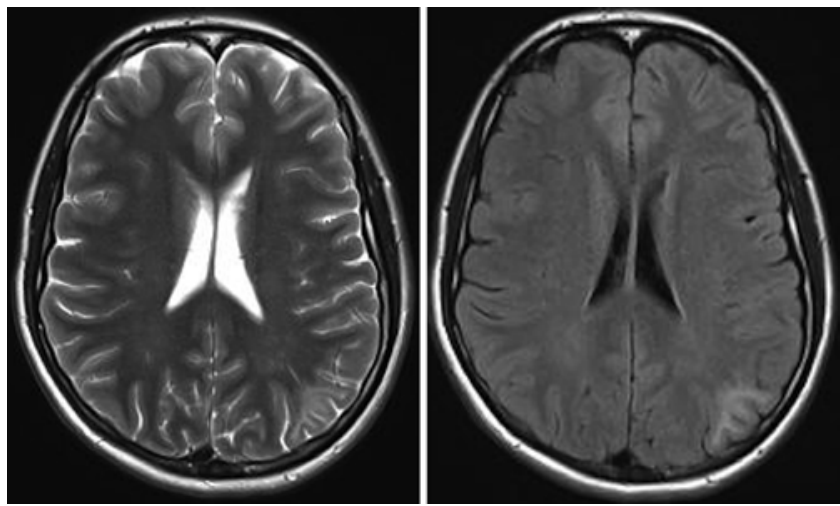

FIG. 2. Illustrative Case 2. Axial T2-weighted (left) and FLAIR (right) MRI studies demonstrate evidence of left parietal nonhemorrhagic contusion.

These cases highlight the need to consider MRI in pediatric patients with focal neurological deficits, worrisome symptoms, or abnormal or inconclusive CT findings. MRI should also be considered in pediatric patients with persistent symptoms for which the definition is unclear. The vast majority of children and adolescents reach symptomatic recovery within 1-4 weeks, although approximately $15 \%-$ $20 \%$ will remain symptomatic beyond 1 month. $13,17,34,40$ Risk factors for prolonged recovery may include female sex, LOC, and a history of concussions, attention deficit hyperactivity disorder, migraine headaches, and learning disorders. ${ }^{25,28,39}$ Physicians caring for pediatric patients with SRC must take into account all of these factors as well as the trajectory of concussion symptoms and physical examination findings when making the decision to order neuroimaging. These decisions are also impacted by the clinical experience and training of the treating physician as well as his or her familiarity with neurological conditions that can potentially mimic or can also co-occur in the setting of SRC. Such complexities underscore the value of multidisciplinary pediatric concussion programs that have the clinical neurological expertise and diagnostic resources to comprehensively address patients with SRC who have persistent symptoms.

At present, there are limited practice guidelines to direct clinical SRC decision making in children and adolescents who are found to have traumatic lesions on neuroimaging. Although there is some literature to suggest that patients with abnormalities on CT or MRI studies should be advised to retire from contact sports, ${ }^{10,11}$ these recommendations do not specifically address recent advances in SWI and GRE imaging that are capable of demonstrating traumatic abnormalities that would have otherwise escaped detection with conventional MRI studies. Whether the presence of traumatic lesions on neuroimaging following SRC is a reflection of an unrecognized genetic susceptibility to head injury is not known. Based on the available literature and guidance by a second opinion from another neurosurgeon, the decision was made to advise both patients who sustained traumatic lesions detected on MRI in this study to retire from contact sports.

Three patients ( 2 boys and 1 girl) in this study were found to have arachnoid cysts, 1 located in the sylvian fis- 
sure (found on CT and MRI) and 2 in the cerebellopontine angle of the posterior fossa ( 1 found on MRI and 1 found on CT). In a large, single-institution series of neuroimaging studies performed in children and adolescents, the prevalence rate for arachnoid cysts was $2.5 \%$, with these abnormalities found more commonly in male patients. ${ }^{1}$ Because of the potential risk of intraarachnoid cyst hemorrhage as well as subdural hematoma and hygroma that can occur following minor head injury, ${ }^{14,38}$ all patients with incidentally discovered arachnoid cysts should undergo consultation with a neurosurgeon to discuss participation in contact sports. In the case of the 2 patients with incidentally discovered posterior fossa arachnoid cysts, both lesions were small with no significant mass effect, and thus both patients were able to return to full sports participation without restriction.

The findings of this study must be evaluated in light of several important limitations. First, patients referred to a multidisciplinary pediatric concussion program may include those with more severe injuries and may thus constitute a population for whom neuroimaging is more likely to be indicated, and with potentially abnormal results, compared with the general pediatric SRC population. Second, patients with traumatic abnormalities identified on initial CT scans following sports-related head trauma may have been referred to other neurosurgeons and not the concussion program, thus reducing the proportion of children with these findings observed in this clinical population. Third, because the majority of CT imaging was performed prior to patient referral to the concussion program, it was not possible to assess whether patients had evidence-based clinical indications for CT imaging. Fourth, the decision to perform MRI was not based on strict predetermined criteria but rather it was based almost entirely on the clinical judgment of a single neurosurgeon. Because of this selection bias, the findings of this study cannot be used to estimate the risk of abnormal MRI findings among a general population of pediatric patients with SRC. Finally, there was considerable variation in MRI protocols across institutions, with not all studies using recent technological advances in SWI or GRE imaging. Therefore, it remains unclear whether standardized incorporation of these sequences in MR imaging protocols would have led to greater detection of cerebral microhemorrhages in this clinical population. To address these limitations, the frequency of abnormal results on neuroimaging in pediatric patients with SRC who have persistent concussion symptoms, focal neurological findings, and an impaired level of consciousness will be addressed by a future prospective study at our institution incorporating these novel structural neuroimaging techniques.

\section{Conclusions}

Preliminary empirical evidence suggests that results of clinical neuroimaging studies are normal in the majority of pediatric patients with SRC. However, in selected cases neuroimaging can provide information that impacts decision making about return to play and retirement from the sport. Evidence-based practice guidelines are urgently needed to help direct clinical decision making when neuroimaging studies demonstrate evidence of traumatic intracranial injury.

\section{Acknowledgment}

We thank the Pan Am Clinic Foundation for their financial support of this study.

\section{References}

1. Al-Holou WN, Yew AY, Boomsaad ZE, Garton HJ, Muraszko KM, Maher CO: Prevalence and natural history of arachnoid cysts in children. J Neurosurg Pediatr 5:578-585, 2010

2. Ashwal S, Babikian T, Gardner-Nichols J, Freier MC, Tong KA, Holshouser BA: Susceptibility-weighted imaging and proton magnetic resonance spectroscopy in assessment of outcome after pediatric traumatic brain injury. Arch Phys Med Rehabil 87 (12 Suppl 2):S50-S58, 2006

3. Atabaki SM, Stiell IG, Bazarian JJ, Sadow KE, Vu TT, Camarca MA, et al: A clinical decision rule for cranial computed tomography in minor pediatric head trauma. Arch Pediatr Adolesc Med 162:439-445, 2008

4. Aubry M, Cantu R, Dvorak J, Graf-Baumann T, Johnston K, Kelly J, et al: Summary and agreement statement of the First International Conference on Concussion in Sport, Vienna 2001. Recommendations for the improvement of safety and health of athletes who may suffer concussive injuries. Br J Sports Med 36:6-10, 2002

5. Babikian T, Freier MC, Tong KA, Nickerson JP, Wall CJ, Holshouser BA, et al: Susceptibility weighted imaging: neuropsychologic outcome and pediatric head injury. Pediatr Neurol 33:184-194, 2005

6. Beauchamp MH, Beare R, Ditchfield M, Coleman L, Babl FE, Kean M, et al: Susceptibility weighted imaging and its relationship to outcome after pediatric traumatic brain injury. Cortex 49:591-598, 2013

7. Beauchamp MH, Ditchfield M, Babl FE, Kean M, Catroppa $\mathrm{C}$, Yeates KO, et al: Detecting traumatic brain lesions in children: CT versus MRI versus susceptibility weighted imaging (SWI). J Neurotrauma 28:915-927, 2011

8. Bodensteiner JB, Schaefer GB, Craft JM: Cavum septi pellucidi and cavum vergae in normal and developmentally delayed populations. J Child Neurol 13:120-121, 1998

9. Brenner D, Elliston C, Hall E, Berdon W: Estimated risks of radiation-induced fatal cancer from pediatric CT. AJR Am J Roentgenol 176:289-296, 2001

10. Cantu RC: Recurrent athletic head injury: risks and when to retire. Clin Sports Med 22:593-603, x, 2003

11. Cantu RC, Register-Mihalik JK: Considerations for returnto-play and retirement decisions after concussion. PM R 3 (10 Suppl 2):S440-S444, 2011

12. Choe MC, Babikian T, DiFiori J, Hovda DA, Giza CC: A pediatric perspective on concussion pathophysiology. Curr Opin Pediatr 24:689-695, 2012

13. Collins M, Lovell MR, Iverson GL, Ide T, Maroon J: Examining concussion rates and return to play in high school football players wearing newer helmet technology: a three-year prospective cohort study. Neurosurgery 58:275-286, 2006

14. Cress M, Kestle JR, Holubkov R, Riva-Cambrin J: Risk factors for pediatric arachnoid cyst rupture/hemorrhage: a casecontrol study. Neurosurgery 72:716-722, 2013

15. Davis RL, Mullen N, Makela M, Taylor JA, Cohen W, Rivara FP: Cranial computed tomography scans in children after minimal head injury with loss of consciousness. Ann Emerg Med 24:640-645, 1994

16. Dunning J, Daly JP, Lomas JP, Lecky F, Batchelor J, Mackway-Jones K: Derivation of the children's head injury algorithm for the prediction of important clinical events decision rule for head injury in children. Arch Dis Child 91:885-891, 2006

17. Eisenberg MA, Meehan WP III, Mannix R: Duration and course of post-concussive symptoms. Pediatrics 133:9991006,2014 
18. Giza CC, Hovda DA: The neurometabolic cascade of concussion. J Athl Train 36:228-235, 2001

19. Giza CC, Kutcher JS, Ashwal S, Barth J, Getchius TS, Gioia GA, et al: Summary of evidence-based guideline update: evaluation and management of concussion in sports: report of the Guideline Development Subcommittee of the American Academy of Neurology. Neurology 80:2250-2257, 2013

20. Hall P, Adami HO, Trichopoulos D, Pedersen NL, Lagiou P, Ekbom A, et al: Effect of low doses of ionising radiation in infancy on cognitive function in adulthood: Swedish population based cohort study. BMJ 328:19, 2004

21. Halstead ME, Walter KD: Clinical report-sport-related concussion in children and adolescents. Pediatrics 126:597-615, 2010

22. Harmon KG, Drezner JA, Gammons M, Guskiewicz KM, Halstead M, Herring SA, et al: American Medical Society for Sports Medicine position statement: concussion in sport. Br J Sports Med 47:15-26, 2013

23. Klassen TP, Reed MH, Stiell IG, Nijssen-Jordan C, Tenenbein M, Joubert G, et al: Variation in utilization of computed tomography scanning for the investigation of minor head trauma in children: a Canadian experience. Acad Emerg Med 7:739-744, 2000

24. Kuppermann N, Holmes JF, Dayan PS, Hoyle JD Jr, Atabaki SM, Holubkov R, et al: Identification of children at very low risk of clinically-important brain injuries after head trauma: a prospective cohort study. Lancet 374:1160-1170, 2009

25. Kutcher JS, Eckner JT: At-risk populations in sports-related concussion. Curr Sports Med Rep 9:16-20, 2010

26. Langlois JA, Rutland-Brown W, Wald MM: The epidemiology and impact of traumatic brain injury: a brief overview. $\mathbf{J}$ Head Trauma Rehabil 21:375-378, 2006

27. Maguire JL, Boutis K, Uleryk EM, Laupacis A, Parkin PC: Should a head-injured child receive a head CT scan? A systematic review of clinical prediction rules. Pediatrics 124:e145-e154, 2009

28. Makdissi M, Davis G, Jordan B, Patricios J, Purcell L, Putukian M: Revisiting the modifiers: how should the evaluation and management of acute concussions differ in specific groups? Br J Sports Med 47:314-320, 2013

29. Maugans TA, Farley C, Altaye M, Leach J, Cecil KM: Pediatric sports-related concussion produces cerebral blood flow alterations. Pediatrics 129:28-37, 2012

30. Mayer AR, Ling JM, Yang Z, Pena A, Yeo RA, Klimaj S: Diffusion abnormalities in pediatric mild traumatic brain injury. J Neurosci 32:17961-17969, 2012

31. McCrory P, Johnston K, Meeuwisse W, Aubry M, Cantu R, Dvorak J, et al: Summary and agreement statement of the 2nd International Conference on Concussion in Sport, Prague 2004. Br J Sports Med 39:196-204, 2005

32. McCrory P, Meeuwisse W, Johnston K, Dvorak J, Aubry M, Molloy M, et al: Consensus Statement on Concussion in Sport: the 3rd International Conference on Concussion in Sport held in Zurich, November 2008. Br J Sports Med 43 (Suppl 1):i76-i90, 2009

33. McCrory P, Meeuwisse WH, Aubry M, Cantu B, Dvorák J, Echemendia RJ, et al: Consensus statement on concussion in sport: the 4th International Conference on Concussion in Sport held in Zurich, November 2012. Br J Sports Med 47:250-258, 2013
34. Meehan WP III, Mannix RC, Stracciolini A, Elbin RJ, Collins MW: Symptom severity predicts prolonged recovery after sport-related concussion, but age and amnesia do not. J Pediatr 163:721-725, 2013

35. Oman JA, Cooper RJ, Holmes JF, Viccellio P, Nyce A, Ross SE, et al: Performance of a decision rule to predict need for computed tomography among children with blunt head trauma. Pediatrics 117:e238-e246, 2006

36. Osmond MH, Klassen TP, Wells GA, Correll R, Jarvis A, Joubert G, et al: CATCH: a clinical decision rule for the use of computed tomography in children with minor head injury. CMAJ 182:341-348, 2010

37. Palchak MJ, Holmes JF, Vance CW, Gelber RE, Schauer BA, Harrison MJ, et al: A decision rule for identifying children at low risk for brain injuries after blunt head trauma. Ann Emerg Med 42:492-506, 2003

38. Parsch CS, Krauss J, Hofmann E, Meixensberger J, Roosen $\mathrm{K}$ : Arachnoid cysts associated with subdural hematomas and hygromas: analysis of 16 cases, long-term follow-up, and review of the literature. Neurosurgery 40:483-490, 1997

39. Scopaz KA, Hatzenbuehler JR: Risk modifiers for concussion and prolonged recovery. Sports Health 5:537-541, 2013

40. Tator $\mathrm{CH}$ : Concussions and their consequences: current diagnosis, management and prevention. CMAJ 185:975-979, 2013

41. Tong KA, Ashwal S, Holshouser BA, Nickerson JP, Wall CJ, Shutter LA, et al: Diffuse axonal injury in children: clinical correlation with hemorrhagic lesions. Ann Neurol 56:36-50, 2004

42. Tong KA, Ashwal S, Holshouser BA, Shutter LA, Herigault G, Haacke EM, et al: Hemorrhagic shearing lesions in children and adolescents with posttraumatic diffuse axonal injury: improved detection and initial results. Radiology 227:332-339, 2003

43. Yang Z, Yeo RA, Pena A, Ling JM, Klimaj S, Campbell R, et al: An FMRI study of auditory orienting and inhibition of return in pediatric mild traumatic brain injury. J Neurotrauma 29:2124-2136, 2012

\section{Author Contributions}

Conception and design: Ellis, Leiter, McDonald, Sawyer, Silver. Acquisition of data: Hall. Analysis and interpretation of data: Hall, Bunge, Essig. Drafting the article: Ellis. Critically revising the article: all authors. Reviewed submitted version of manuscript: all authors. Approved the final version of the manuscript on behalf of all authors: Ellis. Study supervision: Ellis.

\section{Supplemental Information \\ Previous Presentation}

This work was presented as a poster at the 2014 AANS Pediatric Section meeting, which was held on Amelia Island, FL, on December 2-5, 2014.

\section{Correspondence}

Michael Ellis, Pan Am Clinic, 75 Poseidon Bay, Winnipeg, MB R3M 3E4, Canada. email: mellis3@panamclinic.com. 